\title{
Línea base de indicadores de apropiación de TIC en instituciones educativas ${ }^{1}$
}

\section{Isabel Cristina Ángel Uribe}

orcid.org/oooo-0oo2-7886-7267

Universidad Pontificia Bolivariana,

Colombia

isabel.angel@upb.edu.co

\section{María Ruth Patiño Lemos}

orcid.org/0000-0002-7975-0116

Universidad Pontificia Bolivariana,

Colombia

maria.patino@upb.edu.co

\section{Resumen}

Este artículo presenta los resultados de la aplicación de una metodología para la autoevaluación colegiada de la apropiación integral de las TIC en dos Instituciones Educativas (IE) oficiales. Se aplicaron 40 encuestas y 8 entrevistas a docentes, se observaron los recursos (planes de aula y blogs) de los docentes entrevistados, se realizaron 3 entrevistas a administrativos y una lista de chequeo, en la que se tuvo como referente el proyecto educativo institucional, el manual de convivencia y la información de la planeación de los espacios, equipos, recursos TIC, entre otros. La sistematización y análisis de la información se realizó con un software propio: BaseTIC. Los resultados en cuanto a la apropiación de TIC muestran avances en el nivel macro y mesocurricular, mientras que en el nivel microcurricular se sigue haciendo un uso básico de las tecnologías en los procesos educativos y permanece la distancia entre el ser y el saber con el hacer de los docentes. La valoración del proceso investigativo, en sí mismo, permite concluir que, para abordar este tipo de proyectos, son condiciones necesarias la formación conceptual y pedagógica en TIC y la formación en investigación educativa de los docentes, al igual que una gestión administrativa desde la IE que garantice la consolidación y compromiso del equipo de investigadores, que representen los intereses de toda la comunidad académica. La ausencia de estas con-

$1 \quad$ El presente artículo es resultado del proyecto de investigación "Relación entre innovación pedagógica y apropiación de TIC en la Institución Educativa" del Grupo Educación en Ambientes Virtuales (EAV) de la Universidad Pontificia Bolivariana (UPB) que se enmarca en el programa de investigación de la Alianza CIER Occidente "La apropiación pedagógica de las TIC en las escuelas innovadoras", financiado con recursos del Ministerio de Educación Nacional y la gestión de Colciencias. 
diciones evidencia que el ejercicio autoevaluativo de la apropiación TIC se desarrolla a partir de las percepciones e imaginarios de algunos pocos, que no necesariamente representan la realidad institucional y tiene consecuencias en el empoderamiento de la metodología propuesta.

\title{
Palabras clave (fuente: tesauro de la Unesco)
}

Autoevaluación; indicadores educativos; instituciones educativas; establecimientos de enseñanza; investigación evaluativa; práctica educativa; tecnologías de información y comunicación; TIC.

\section{Baseline of ICT Adoption Indicators in Educational Institutions ${ }^{1}$}

\author{
Abstract
}

This article presents the results of applying a methodology for collegiate self-assessment of comprehensive ICT adoption to two public Educational Institutions (EI). Forty surveys and eight interviews were conducted with teachers; their resources (lesson plans and blogs) were observed; three administrative staff members were interviewed; and a checklist was completed, which included the institutional educational project, school rules and regulations, and the information of the planning of spaces, equipment, ICT resources, etc. Data systematization and analysis were carried out using our own software: BaseTIC. The results of ICT adoption show advances at the macro- and meso-curricular level, while at the micro-curricular level, technologies are still given a basic use in the educational processes and the gap between teachers' being/knowledge and practice remains. The research process assessment itself allows to conclude that this type of project requires that teachers have conceptual and pedagogical ICT training and educational research training and that the EI administrative management ensures the consolidation and commitment of a research team that represents the interests of the entire academic community. The absence of these conditions makes clear that ICT adoption self-assessment is made from the perceptions and imaginary of a few, which do not necessarily represent the institutional reality and has effects on the empowerment of the proposed methodology.

\section{Keywords (Source: Unesco Thesaurus)}

Self evaluation; educational indicators; educational institutions; educational research; educational practice; information and communication technologies; ICT.

1 This article is the result of the research project "Relationship between pedagogical innovation and ICT adoption in an Educational Institution" of the Education in Virtual Environments Group (EAV) of the Universidad Pontificia Bolivariana (UPB). It is part of the research program of the Alianza CIER Occidente "Pedagogical ICT adoption in innovative schools" financed with resources from the Ministry of National Education and managed by Colciencias. 


\title{
Linha base de indicadores de apropriação TIC em instituições educativas ${ }^{1}$
}

\author{
Resumo
}

Este artigo apresenta os resultados da aplicação de uma metodologia para a autoavaliação colegiada da apropriação integral das TIC em duas Instituições Educativas (IE) oficiais. Foram aplicadas 40 enquetes e 8 entrevistas a professores, foram observados os recursos (planos de aula e blogs) dos docentes entrevistados e também foram realizadas 3 entrevistas a funcionários administrativos e uma lista de checagem, na qual constava como referente no projeto educativo institucional, o manual de convivência e a informação do planejamento dos espaços, equipamentos, recursos TIC, entre outros. A sistematização e análise da informação foi realizada com um software próprio: BaseTIC. Os resultados relacionados à apropriação de TIC mostram avanços no âmbito macro e mesocurricular, enquanto no âmbito microcurricular segue-se fazendo um uso básico das tecnologias nos processos educativos e permanece a distância entre o ser e o saber com o fazer dos docentes. A valorização do processo de pesquisa, por si só, permite concluir que, para abordar esse tipo de projetos a formação conceitual e pedagógica em TIC e a formação em pesquisa educativa dos docentes são condições necessárias, bem como uma gestão administrativa a partir da IE que garanta a consolidação e o compromisso da equipe de pesquisadores, que representem os interesses de toda a comunidade acadêmica. A ausência dessas condições evidencia que o exercício autoavaliativo da apropriação TIC se desenvolve a partir das percepções e imaginários de alguns poucos, que não necessariamente representam a realidade institucional e isso tem consequências no empoderamento da metodologia proposta.

\section{Palavras-chave (Fonte: tesauro da UnEsco)}

Autoavaliação; indicadores educacionais; instituições educativas; estabelecimentos de ensino; pesquisa de avaliação; prática educativa; novas tecnologias de informação e comunicação; NTIC.

1 O presente artigo é resultado do projeto de pesquisa "Relação entre inovação pedagógica e apropriação de TIC na Instituição Educativa" do Grupo Educação em Ambientes Virtuais (EAV) da Universidade Pontifícia Bolivariana (UPB) que se enquadra no programa de pesquisa da Aliança CIER Ocidente "A apropriação pedagógica das TIC escolas inovadoras", financiado com recursos do Ministério de Educação Nacional e da gestão de Colciencias. 
Entre las políticas para la calidad educativa que define el Ministerio de Educación Nacional (MEN), el uso de las Tecnologías de Información y Comunicación (TIC) juega un papel preponderante y plantea retos de transformación de las prácticas de enseñanza y aprendizaje. La incorporación de TIC ha dejado de ser una opción para convertirse en una realidad y exigencia para los docentes (MEN, 2006). Entendida como la interacción y mediación tecnológica/pedagógica (Giraldo, 2006), dicha apropiación de las TIC en la educación obliga a los docentes a reconsiderar su rol como sujetos reflexivos, críticos y productores de conocimiento, atentos a las nuevas dinámicas del contexto. En términos de Chaves (2001), se trata de repensar la práctica frente a las implicaciones educativas de la teoría sociocultural de Vigotsky. La apropiación "no implica solo un hacer, sino un ser que exige un reconocimiento de lo que se hace, del porqué se hace, del para qué se hace" (Álvarez, Vega y Álvarez, 2011, p. 58). Ello genera formas de relación que propician la intención pedagógica de las acciones de las prácticas docentes. Rodríguez y Ocampo lo reafirman en su estudio:

[...] la apropiación de las TIC en la educación más que dotación y capacitaciones requiere de espacios de socialización y de reflexión, en los cuales el lenguaje y sus juegos conformen el contexto para poder interactuar en las diversas experiencias de los sujetos implicados en dicho proceso; no se trata de estandarizar $u$ homogeneizar las experiencias con las TIC, sino de ver en las semejanza y desemejanzas de dicho proceso un pluralismo que acoge están nuevas lógicas actuando a la par de los cambios y transformaciones que la educación actual demanda. (2014, p. 139)

Las evaluaciones de los usos de las TIC en las Instituciones Educativas (IE) difícilmente dan cuenta de la apropiación por parte de los docentes (Giraldo y Patiño, 2009; Vallejo y Patiño, 2011; 2013), dado su carácter cuantitativo y externo. Propuestas con una mirada cuantitativa del uso de las TIC en la educa- ción -como las de Sunkel (2006), Ministerio de Comunicaciones (2008), Unesco (2009); UIT (2010), Severin (2010), Claro (2010), Hinostroza y Labbé (2011), Patiño (2013), Sunkel, Trucco y Espejo (2014), Cepal (2015)- evidencian la necesidad de tener indicadores tanto locales como cualitativos. Otros estudios del uso de las TIC, como los de Lugo y Kelly (2011), OEI y Fundación Telefónica (2011), Fuentes (2013), tienen una mirada más cualitativa donde el instrumento por excelencia de recolección de la información es un cuestionario, diligenciado individual o grupalmente a partir del diálogo.

Diversidad de iniciativas tejen, en parte, el complejo panorama de los usos y apropiación de las TIC en el ámbito educativo, con alcances particulares: Taquez, Rengifo y Mejía (2017) y Peeraer y Van Petegem (2011) proponen un único instrumento, de carácter cuantitativo, para reconocer las necesidades de formación que tienen los docentes en su práctica, en varias dimensiones. Melgarejo y Rodríguez (2016), con un análisis cuantitativo de los datos, también retoman propuestas foráneas para el seguimiento y evaluación de la inclusión de TIC. Ávila y Riascos (2011), aunque cuentan con ambos enfoques (cualitativo y cuantitativo), tienen como objeto componentes muy específicos (pedagógico y de infraestructura TIC); otros, como Valencia et al. (2016), tienen en cuenta particularmente la práctica del docente con TIC, y algunos, como Erstad (2009) y Mominó y Carrere (2016), presentan un enfoque sistémico en el que reconocen el rol de las TIC en toda la estructura del sistema educativo.

La metodología para la apropiación integral de TIC en la institución educativa (Patiño y Vallejo, 2013; Ángel, Patiño y Vallejo, 2017) desarrollada por el Grupo de Investigación Educación en Ambientes Virtuales (EAV)' de la Universidad Pontificia Bolivariana (UPB)

1 Esta metodología es producto de la trayectoria investigativa del grupo EAV entre 2005-2015: Propuesta para la apropiación de TIC en los procesos de enseñanza y de aprendizaje en la UPB; Diseño de una propuesta metodológica para el monitoreo y análisis de usos de TIC por parte de comunidades vulnerables de Medellín; 
se presenta como una alternativa para la autoevaluación TIC donde prima una mirada cualitativa y holística de los usos. La aplicación de esta Metodología parte de un ejercicio de reconocimiento del contexto de las IE para construir, conjuntamente con los actores de la IE, su propia línea base de indicadores TIC y respectivos planes de mejoramiento en pro de la calidad académica de su institución. Son entonces las comunidades académicas, conformadas por directivos, docentes y estudiantes, los autores principales de la evaluación de la apropiación TIC.

En sintesis, el ejercicio autoevaluativo, que MacBeath (2005) entiende como la autorreflexión crítica de un sistema de evaluación escolar saludable, permite identificar el estado de los procesos de incorporación, integración y apropiación tecnológica, para lo cual la Metodología propone que las comunidades académicas, por medio de un proceso formativo e investigativo: 1) reflexionen y autoevalúen colaborativa e interdisciplinarmente sus procesos educativos con una mirada multidimensional del estado de la apropiación TIC; 2) construyan una línea base de indicadores TIC, la primera de muchas, de evaluación cíclica, como lo proponen Mominóy Carrere (2016);y3) seempoderen de la toma de decisiones para las trasformaciones en términos de apropiación. Castro afirma que "la investigación acompaña la innovación a partir de la evaluación permanente del estado de la misma, con sus diversos impactos y su costo efectividad en relación con otras alternativas" (2006, p. 102), y de ahí la importancia de que las IE involucren la cultura de la autoevaluación en pro de la calidad educativa y como sustento de la toma de decisiones. Como

Diseño de una propuesta comunicativo-pedagógica de formación en los usos y apropiación de las TIC digitales para la vida cotidiana y el ámbito educativo de comunidades vulnerables; Propuesta de una línea base para indicadores de usos y apropiación de TIC que permita evaluar procesos de inclusión digital; Premios a la calidad de la educación en las convocatorias "Medellín, maestros para la vida": estudio de la inclusión digital como eje transversal en los procesos de mejoramiento de la calidad educativa, y Relación entre innovación pedagógica y apropiación de TIC en la IE. lo expone García (2003), la autoevaluación es una oportunidad para identificar debilidades, fortalezas y necesidades propias, especialmente cuando tienen una aproximación cualitativa, que no replica modelos o aplica estándares de otras realidades y contextos, sino que responde a la autonomía y la particularidad institucional determinadas por los sujetos que la componen.

La multidimensionalidad a la que se refiere el proceso (Johannessen, 2009) y en la que se sustenta la Metodología (Vallejo y Patiño, 2013; 2014) plantea la interdependencia entre las dimensiones teórica, práctica, humana y material y el uso de diversas fuentes de información. Las TIC incuestionablemente se cruzan con la fundamentación conceptual (dimensión teórica), los usos de las TIC en las actividades de enseñanza y de aprendizaje (dimensión práctica), las competencias TIC de los docentes, desde el ser, el saber y el hacer (dimensión humana), y la infraestructura tecnológica de la institución educativa que soporta los procesos académicos y administrativos (dimensión material), y este entramado es el que permite acercarse a la valoración de la apropiación tecnológica en las IE.

\section{Metodología}

Esta experiencia investigativa tiene un enfoque cualitativo, que pretende conocer una realidad susceptible de descripción, interpretación y construcción de sentidos con base en los discursos y las prácticas de los sujetos. Al mismo tiempo, valida la Metodología propuesta y forma a las comunidades académicas en procesos de investigación evaluativa (Vallejo y Patiño, 2013; Patiño y Vallejo, 2013; Ángel et al., 2014). La población la constituyen diez escuelas innovadoras, de carácter oficial, del Centro de Innovación Educativa Regional (CIER) Occidente. Y el muestreo, no probabilístico, lo conforman los colegios Loyola para la Ciencia y la Innovación y Manuel Uribe Ángel (MUA). El equipo de investigadores del Colegio Loyola lo configuran tres docentes y quince estudiantes y el del MUA tres docentes, ocho estu- 
diantes y un administrativo, responsables de liderar la investigación y el trabajo con sus respectivas comunidades académicas.

El proyecto plantea dos fases: una descriptiva (proceso investigativo interno de la IE) y otra de interpretación (proceso de investigación externo por la UPB). En la primera se forma conceptual y metodológicamente a las comunidades educativas y se diseñan, aplican y analizan los siguientes instrumentos de investigación: encuestas y entrevistas a docentes, listas de chequeo de documentos rectores, entrevista a administrativos y observación de recursos, que aportan información a las diferentes dimensiones, cuyos criterios han sido ajustados por el equipo investigador de cada IE para el levantamiento de su línea base de indicadores TIC. En la Tabla 1 se detallan los componentes de cada uno de los instrumentos. De esta forma, las comunidades académicas (investigadores internos de la IE), con el acompañamiento de asesores externos (investigadores de la UPB) concretan su propia línea base de indicadores de apropiación TIC. La aplicación de los instrumentos de esta experiencia investigativa se lleva a cabo de la siguiente manera:

- Encuesta a docentes: se aplica en línea en el software BaseTIC ${ }^{2}$ haciendo uso de los computadores de las IE.

- Lista de chequeo: es verificada por estudiantes de pregrado de la UPB a partir de los siguientes documentos rectores: proyecto educativo institucional, manual de convivencia, programas, proyectos y planes, y consulta a coordinadores y directivos.

- Entrevistas a docentes: aplicadas por estudiantes de maestría de la UPB como parte de su trabajo de grado (Tamayo y Restrepo, 2015), al igual que la observación de los recursos, tales

2 BaseTIC es un software diseñado por el grupo EAV producto del proyecto de investigación al que se refiere este artículo. Registro de derechos de autor: 13-51-224 de año 2016. como: objetos de aprendizaje, planes de aula, mallas curriculares y blogs, disponibles en las páginas institucionales o referenciados por los coordinadores.

- $\quad$ Entrevistas a directivos (rectores y coordinadores): aplicadas por los investigadores de la UPB.

Los datos provenientes de los cinco instrumentos de investigación se codifican respondiendo a la estructura jerárquica de la línea base de indicadores de apropiación TIC, conformada por cuatro dimensiones (categorías de análisis), 13 componentes, 28 aspectos y 137 criterios (Tabla 2); y se sistematizan en el software BaseTIC como insumo para la valoración cualitativa y cuantitativa de los criterios y formulación de los planes de mejoramiento de cada IE.

Los docentes investigadores de las IE, en discusión académica, teniendo en cuenta su contexto y con los datos de los instrumentos aplicados ya sistematizados en el software BaseTIC, realizan una valoración cualitativa y cuantitativa de los 137 criterios (que se despliegan de los "Aspectos" presentados en la Tabla 2) y que constituyen la línea base de indicadores de apropiación TIC de cada IE, sobre las cuales se realiza el análisis de resultados para este artículo (segunda fase del proyecto). A manera de ejemplo, se presentan en el Tabla 3 las valoraciones realizadas por los maestros de tres de estos criterios propuestos.

En la segunda fase, de interpretación, los investigadores de la UPB, a partir de los datos sistematizados en el software BaseTIC, realizan un análisis estadístico para los datos cuantitativos, y para los cualitativos, una reducción por medio de codificación, categorización y triangulación. Finalmente, se contrastan estos resultados con la línea base de indicadores construida por los docentes investigadores de cada IE para presentar conclusiones en términos de la Metodología como estrategia para la autoevaluación de la apropiación TIC (Vallejo y Patiño, 2013). 
Tabla 1. Relación entre los instrumentos de investigación, las dimensiones y sus componentes

\begin{tabular}{|c|c|c|c|c|c|c|}
\hline Dimensión & Componente & Encuesta & Lista chequeo & $\begin{array}{l}\text { Entrevista } \\
\text { directivos }\end{array}$ & $\begin{array}{c}\text { Entrevista } \\
\text { docentes }\end{array}$ & $\begin{array}{l}\text { Observación } \\
\text { recursos }\end{array}$ \\
\hline \multirow{4}{*}{ Teórica } & Políticas públicas & $x$ & & & $x$ & \\
\hline & Marco teórico & & $x$ & $x$ & & \\
\hline & Proyecto educativo institucional (PEI) & $x$ & $x$ & $x$ & & \\
\hline & Gestión recursos tecnológicos & $x$ & $x$ & $x$ & & \\
\hline \multirow{4}{*}{ Práctica } & Interacción & $x$ & & & $x$ & $x$ \\
\hline & Procesos de indagación e investigación & $x$ & & & $x$ & $x$ \\
\hline & Procesos de lectura y escritura & $x$ & & & $x$ & $x$ \\
\hline & Procesos de evaluación & $x$ & & & $x$ & $x$ \\
\hline \multirow{5}{*}{ Humana } & Pedagógico & $x$ & & & $x$ & \\
\hline & Formación profesional & $x$ & & & $x$ & \\
\hline & Social y ético & $x$ & & & & \\
\hline & Organizacional / administrativo & $x$ & & & $x$ & $x$ \\
\hline & Técnico & $x$ & & & $x$ & \\
\hline Material & Infraestructura tecnológica & $x$ & $x$ & $x$ & $x$ & \\
\hline
\end{tabular}

Fuente: Elaboración propia.

Tabla 2. Estructura línea base de indicadores de apropiación TIC

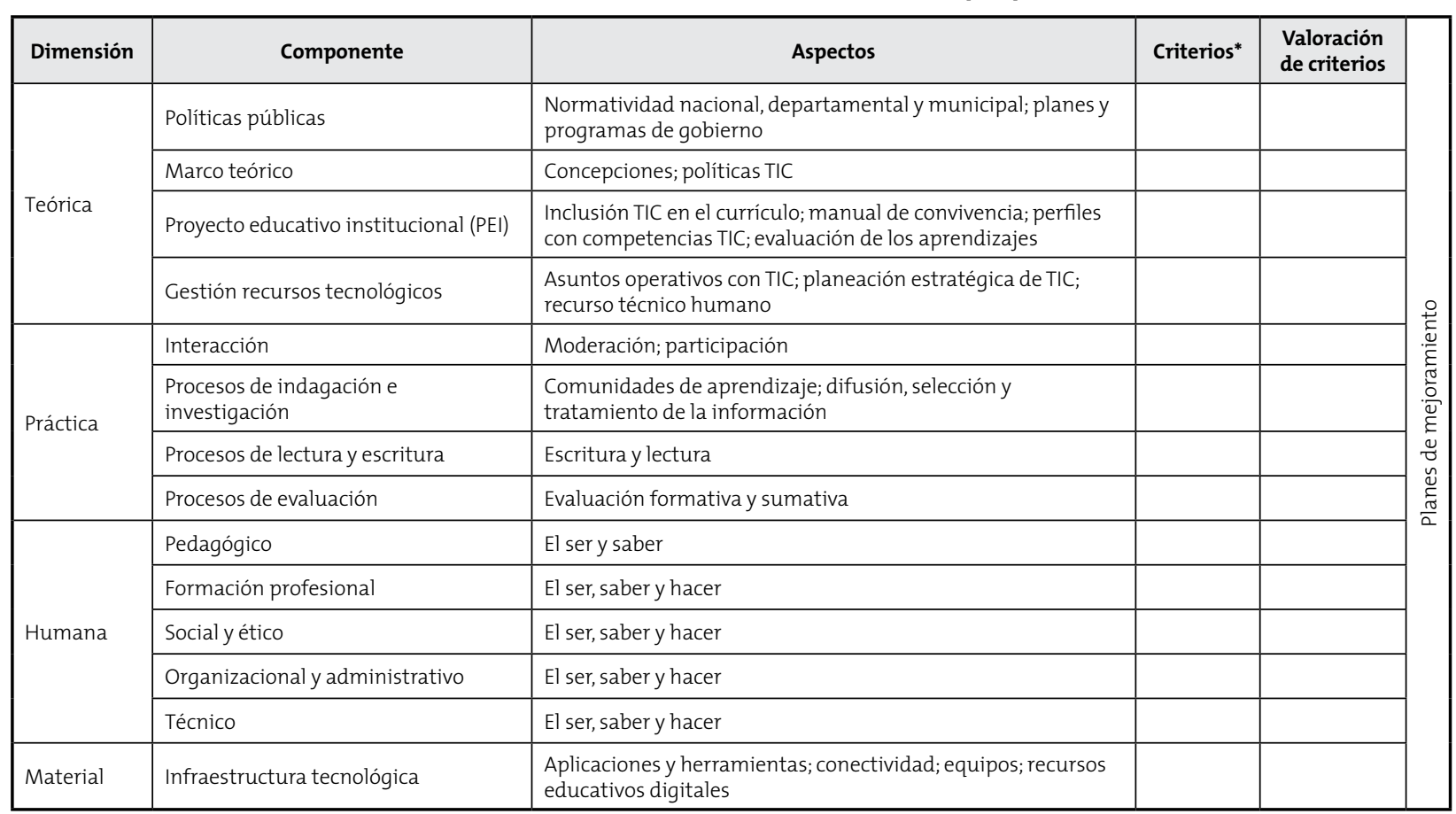

Fuente: elaboración propia. ${ }^{*}$ No se despliegan los 137 criterios, por su extensión. 
Tabla 3. Ejemplo de valoración cualitativa y cuantitativa de los criterios de una de las IE extraída del software BaseTIC

\begin{tabular}{|c|c|}
\hline \multicolumn{2}{|c|}{ T.1.3.1 - Conocimiento de los planes y programas de gobierno en materia de TIC que afectan a las IE } \\
\hline Valoración cuantitativa & $50 \%$ \\
\hline Valoración cualitativa & $\begin{array}{l}\text { Hace falta socializar procesos que permita evidenciar el verdadero conocimiento de las } \\
\text { políticas en materia de TIC por parte de los docentes; no se puede suponer que, por el } \\
\text { hecho de que la institución haya sido creada con énfasis en uso de las TIC, todos los } \\
\text { docentes tengan o deban tener conocimiento pleno de estas políticas. }\end{array}$ \\
\hline \multicolumn{2}{|c|}{ T.1.3.2 - Identificación de las oportunidades para la IE a partir de estos planes y programas } \\
\hline Valoración cuantitativa & $70 \%$ \\
\hline Valoración cualitativa & $\begin{array}{l}\text { Un gran número de docentes han realizado cursos de formación ofrecidos por la } \\
\text { Secretaría de Educación, como la ruta TIC, con participación en el proyecto de las Escuelas } \\
\text { Innovadoras del Ministerio, Computadores para Educar, eventos promovidos por Ruta } \\
\text { N y Parque Explora, Ciudadanía Digital. Se permiten los espacios de formación de los } \\
\text { maestros para los procesos de formación. }\end{array}$ \\
\hline \multicolumn{2}{|c|}{ T.2.1.1 - Declaración de una política institucional en relación con el uso de las TIC } \\
\hline Valoración cuantitativa & $100 \%$ \\
\hline Valoración cualitativa & El PEl y los planes de área son documentos que están en constante revisión y construcción. \\
\hline
\end{tabular}

Fuente: elaboración propia.

\section{Resultados}

Los resultados se presentan para las cuatro dimensiones (categorías del análisis), a partir de las cuales las IE construyeron su línea base de indicadores de la apropiación TIC. Es de anotar que: 1) en los análisis no se nombran las IE del estudio de forma particular; 2) todos los criterios se refieren al uso de las TIC en los procesos educativos, y 3 ) en los análisis de las encuestas se habla de calificación alta, haciendo con ello referencia a la suma de las valoraciones 4 y 5 de la escala utilizada³.

\section{Dimensión teórica}

Esta dimensión da cuenta de la fundamentación conceptual de las TIC en la IE, consignada en los documentos institucionales. La integran los componentes de: políticas públicas, marco teórico, proyecto institucional y gestión. En promedio, un $54 \%$ de los

3 En las encuestas, para dar respuesta a cada una de las preguntas, se utiliza una escala de 1 a 5 , Así: 1 = Nunca, 2 = Casi nunca, $3=$ Algunas veces, $4=$ Casi siempre y $5=$ Siempre docentes califican como alto su conocimiento de las políticas públicas TIC y los directivos enuncian que existe una relación permanente con las directrices de las secretarías de educación y del MEN, lo que conlleva una alineación del PEI con las políticas TIC (nacionales, departamentales y locales). La participación en los programas de formación ofrecidos por los entes gubernamentales es considerada como una oportunidad para el mejoramiento de la calidad educativa.

Los directivos señalan que las TIC están presentes en varios aspectos del currículo: perfil docente; competencias de los estudiantes; relación entre las TIC y los procesos investigativos y participación de los docentes en la construcción del currículo, lo que se evidencia en los PEl:

Formar excelentes bachilleres y ciudadanos de las comunidades de Medellín caracterizados por sus competencias, talento y creatividad, a través del uso intensivo de altas tecnologías, 
ambientes de aprendizaje innovadores y personal experto, mediante estrategias pedagógicas activas y acceso permanente a la información y la tecnología (IE Loyola, 2010, p. 9).

[...] optimizando los recursos que ofrecen las nuevas tecnologías, que comprometa en los alumnos un cambio en la aplicación de sus saberes, basados en la investigación para llevar a cabo proyectos que redunden en el mejoramiento de la calidad de vida del individuo y su entorno (MUA, 2014, p. 7).

Un 33\% de los docentes califican como alta su participación en la construcción de los reglamentos que rigen el uso de las TIC. En los manuales de convivencia se contemplan deberes y derechos en relación con el uso de las salas de informática. En los PEI se explicita el papel de la tecnología en el desarrollo de los aprendizajes, pero no su rol en los procesos de evaluación, ni las competencias TIC de los docentes y estudiantes. Sin embargo, el discurso de los rectores resalta la importancia de la inclusión de TIC en mallas curriculares, planes de área, trabajo de las comunidades y redes de aprendizaje, formación de estudiantes y docentes, y recalca que estas competencias son un criterio necesario para la selección de docentes.

La revisión de documentos institucionales y las afirmaciones de las directivas evidencian que no existen planes y/o proyectos propios en materia de TIC. Las directivas expresan que existe una alta motivación de los docentes para participar en proyectos de aula y de investigación propuestos por entidades gubernamentales y privadas, como lo evidencia un promedio del $46 \%$ de los docentes que califican como alta su participación en el planteamiento de proyectos y planes TIC.

Las IE no cuentan con un presupuesto para la formación de docentes ni con recurso humano técnico propio para el soporte de los sistemas de información, ya que ambos procesos están centralizados en las secretarías de educación.
El manejo de la información académica se hace principalmente a través del Sistema Integrado de Matricula ${ }^{4}$-utilizado por todas las instituciones educativas colombianas-y de otros programas para la sistematización de notas y procesos evaluativos de docentes y rectores. Se evidencian limitaciones en: gestión de estos sistemas, políticas (ausentes), directrices, procedimientos de mantenimiento y protocolos de seguridad. No se cuenta con un sistema de comunicación entre la comunidad académica y otras instituciones, lo que se suple con el uso de páginas web y Facebook.

Los investigadores de las IE valoraron los componentes de la dimensión teórica con los siguientes promedios (Tabla 4):

Tabla 4. Línea base de indicadores de apropiación TIC - dimensión teórica

\begin{tabular}{|l|c|c|}
\hline \multicolumn{1}{|c|}{ Componente } & IE1 & IE2 \\
\hline Políticas públicas & $55 \%$ & $69 \%$ \\
\hline Marco teórico & $77 \%$ & $85 \%$ \\
\hline Proyecto educativo & $54 \%$ & $71 \%$ \\
\hline Gestión & $43 \%$ & $75 \%$ \\
\hline Promedios & $57 \%$ & $75 \%$ \\
\hline
\end{tabular}

Fuente: elaboración propia.

\section{Dimensión práctica}

La dimensión práctica da cuenta de los usos que hacen los docentes de las TIC en las actividades de enseñanza y de aprendizaje. La constituyen los siguientes componentes: interacción, indagación e investigación, procesos de lectura y escritura y procesos de evaluación. Los criterios que dan cuenta de la interacción la califican como alta más del $60 \%$ de los profesores, exceptuando en lo relacionado con los cierres a discusiones y la creación de grupos de discusión (Tabla 5).

4 Este sistema recoge número de estudiantes matriculados, características socioeconómicas, necesidades educativas especiales, programas especiales de apoyo a los estudiantes, indicadores de desempeño por áreas, entre otros. 
Tabla 5. Componente interacción. Resultados de la encuesta

\begin{tabular}{|c|c|c|c|}
\hline \multirow{2}{*}{ Aspectos } & \multirow{2}{*}{ Criterios } & \multicolumn{2}{|c|}{ Valoración alta } \\
\hline & & IE1 & IE2 \\
\hline \multirow{6}{*}{ Regulación de los aprendizajes } & Recursos didácticos interactivos & $83 \%$ & $57 \%$ \\
\hline & Reorientación discusiones & $75 \%$ & $61 \%$ \\
\hline & Nuevos retos y reformulaciones & $67 \%$ & $75 \%$ \\
\hline & Reflexión y posición crítica & $92 \%$ & $89 \%$ \\
\hline & Cierres a discusiones & $42 \%$ & $21 \%$ \\
\hline & Precisión conceptos procedimientos & $83 \%$ & $75 \%$ \\
\hline \multirow{4}{*}{ Trabajo colaborativo } & Proposición trabajo colaborativo & $92 \%$ & $75 \%$ \\
\hline & Creación de grupos discusión & $50 \%$ & $29 \%$ \\
\hline & Proposición aportes a compañeros & $92 \%$ & $72 \%$ \\
\hline & Valoración de la participación & $67 \%$ & $67 \%$ \\
\hline
\end{tabular}

Fuente: elaboración propia.

Los docentes expresan que utilizan el correo electrónico, Facebook y Whatsapp para la interacción con sus estudiantes, solo uno menciona el foro como herramienta de mediación y en ningún caso se especifica el uso de las TIC en los procesos de evaluación.

En la planeación y desarrollo de actividades de aprendizaje utilizan diversos recursos TIC, pero no explicitan la intención del uso. Para el trabajo colaborativo se emplea el chat de Google, Skype y redes sociales, ocasionalmente Facebook y las páginas institucionales para publicar trabajos de los estudiantes. Utilizan Facebook y Google para realizar acciones de comunicación, intercambio de información y acompañamiento al estudiante, lo que se encuentra aún distante de la construcción de ambientes virtuales de aprendizaje.

En las actividades que dan cuenta del uso de las TIC en los procesos de indagación e investigación los docentes resaltan el uso de fuentes de información, normas de citación y referenciación (Tabla 6). Para promover estos procesos en sus estudiantes dicen hacer uso de Moodle, páginas web, blogs, redes sociales, pero no presentan evidencias de ello.
Tabla 6. Componente indagación e investigación. Resultados de la encuesta

\begin{tabular}{|l|c|c|}
\hline \multirow{2}{*}{ Aspectos } & \multicolumn{2}{c|}{ Valoración alta } \\
\cline { 2 - 3 } & IE1 & IE2 \\
\hline $\begin{array}{l}\text { Uso de fuentes de información, } \\
\text { normas de citación y referenciación }\end{array}$ & $81 \%$ & $54 \%$ \\
\hline $\begin{array}{l}\text { Uso de formatos y criterios para } \\
\text { sistematizar, analizar y sintetizar } \\
\text { información }\end{array}$ & $64 \%$ & $49 \%$ \\
\hline $\begin{array}{l}\text { Creación y participación en redes de } \\
\text { aprendizaje }\end{array}$ & $50 \%$ & $30 \%$ \\
\hline
\end{tabular}

Fuente: elaboración propia.

Las actividades que hacen referencia a los procesos de lectura son valoradas alto por más del $60 \%$ de los docentes, mientras que los procesos de escritura son valorados en promedio por el $52 \%$ (Tabla 7 ).

Tabla 7. Componente lectura y escritura. Resultados de la encuesta

\begin{tabular}{|l|c|c|}
\hline \multirow{2}{*}{ Aspectos } & \multicolumn{2}{c|}{ Valoración alta } \\
\cline { 2 - 3 } & IE1 & IE2 \\
\hline Lectura en diferentes formatos-rutas & $83 \%$ & $57 \%$ \\
\hline Lectura hipertextual & $83 \%$ & $53 \%$ \\
\hline $\begin{array}{l}\text { Lectura literal, intertextual, } \\
\text { inferencial y critica }\end{array}$ & $67 \%$ & $61 \%$ \\
\hline Producción hipertextual & $50 \%$ & $54 \%$ \\
\hline
\end{tabular}

Fuente: elaboración propia. 
Sin embargo, al contrastar estos resultados con el discurso de los profesores, las respuestas no dancuenta de actividades que promuevan procesos de lectura intertextual, inferencial, crítica o hipertextual. En la observación de recursos solo se encuentran enlaces a lecturas complementarias, reseñas bibliográficas y videos, pero no se presentan evidencias de guías para las lecturas hipertextuales ni para la escritura colaborativa. Los usos de las TIC en los procesos de evaluación de los aprendizajes, en relación con los demás componentes de esta dimensión, presentan los porcentajes más bajos (Tabla 8).

Tabla 8. Componente evaluación. Resultados de la encuesta

\begin{tabular}{|l|c|c|}
\hline \multirow{2}{*}{ Aspectos } & \multicolumn{2}{c|}{ Valoración alta } \\
\cline { 2 - 3 } & IE1 & IE2 \\
\hline Concertación criterios de evaluación & $83 \%$ & $57 \%$ \\
\hline $\begin{array}{l}\text { Uso de instrumentos de } \\
\text { autoevaluación }\end{array}$ & $50 \%$ & $28 \%$ \\
\hline $\begin{array}{l}\text { Uso de instrumentos de } \\
\text { coevaluación }\end{array}$ & $41 \%$ & $21 \%$ \\
\hline $\begin{array}{l}\text { Uso de instrumentos de evaluación } \\
\text { en línea }\end{array}$ & $58 \%$ & $25 \%$ \\
\hline $\begin{array}{l}\text { Uso de instrumentos de evaluación } \\
\text { cualitativa }\end{array}$ & $25 \%$ & $49 \%$ \\
\hline
\end{tabular}

Fuente: elaboración propia.

El uso de las TIC en los procesos de evaluación no es un asunto generalizado. Se presentan respuestas diversas: algunos docentes afirman no haber utilizado las TIC para la evaluación formativa ni sumativa. Solo un docente menciona que interactúa con los estudiantes para motivar, aclarar dudas y ampliar información, y otro expresa que realiza actividades de coevaluación tomando como base los aportes realizados por los compañeros en actividades virtuales. Hay consenso en el uso de las TIC para el diseño de las evaluaciones y la sistematización de las notas.

Los investigadores de las IE valoraron los componentes de la dimensión práctica con los siguientes promedios (Tabla 9):
Tabla 9. Linea Base de Indicadores TIC - Dimensión práctica

\begin{tabular}{|l|c|c|}
\hline \multicolumn{1}{|c|}{ Componente } & IE1 & IE2 \\
\hline Interacción & $69 \%$ & $73 \%$ \\
\hline Indagación e investigación & $64 \%$ & $65 \%$ \\
\hline Procesos de lectura y escritura & $70 \%$ & $56 \%$ \\
\hline Procesos de evaluación & $59 \%$ & $68 \%$ \\
\hline Promedios & $66 \%$ & $66 \%$ \\
\hline
\end{tabular}

Fuente: elaboración propia.

\section{Dimensión humana}

La dimensión humana da cuenta de las competencias TIC de los docentes desde el ser, el saber y el hacer, en relación con el campo pedagógico, el desarrollo profesional, el compromiso ético y social, la organización y gestión y las habilidades y destrezas técnicas. La mayoría de los profesores tienen percepciones y actitudes positivas y propositivas acerca de las TIC, como elemento potenciador de los aprendizajes que contribuye al desarrollo de la autonomía de los estudiantes, en la elaboración de recursos y a optimizar su trabajo. Los porcentajes de docentes que califican como alto estas percepciones y comprensiones se muestran en la Tabla 10. Por otra parte, los docentes plantean que los estudiantes se dispersan con internet y se vuelven facilistas y que el mal uso afecta la privacidad y va en detrimento de la vida familiar, pues no hay límites en los horarios de uso.

Las competencias TIC en relación con el desarrollo profesional son valoradas positivamente por un alto porcentaje de docentes, resaltando el conocimiento de los espacios y herramientas para la formación virtual (Tabla 11).

Los profesores perciben que las TIC dinamizan y potencian los procesos de inclusión social, de participación y convivencia ciudadana y democratización del conocimiento. Y si bien un $67 \%$ de los encuestados califica como alto el conocimiento y aplicación de los aspectos legales en el uso de recursos digitales, queda un $33 \%$ que carecen de esta competencia importante para la formación de los estudiantes (Tabla 12). 
Tabla 10. Componente competencias

TIC en relación con el campo pedagógico. Resultados de la encuesta

\begin{tabular}{|c|c|c|c|}
\hline \multirow{2}{*}{ 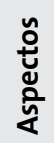 } & \multirow{2}{*}{ Criterios } & \multicolumn{2}{|c|}{$\begin{array}{l}\text { Valoración } \\
\text { alta }\end{array}$} \\
\hline & & IE1 & IE2 \\
\hline \multirow{3}{*}{ 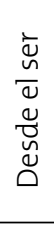 } & Actitud propositiva del uso de TIC & $100 \%$ & $75 \%$ \\
\hline & $\begin{array}{l}\text { Transversalidad TIC en el } \\
\text { currículo }\end{array}$ & $80 \%$ & $89 \%$ \\
\hline & $\begin{array}{l}\text { Percepción positiva - uso } \\
\text { pedagógico }\end{array}$ & $80 \%$ & $100 \%$ \\
\hline \multirow{3}{*}{ 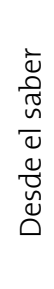 } & $\begin{array}{l}\text { Comprensión mediaciones } \\
\text { tecnológicas }\end{array}$ & $92 \%$ & $100 \%$ \\
\hline & $\begin{array}{l}\text { Diferenciación ambientes } \\
\text { tradicionales y mediados } \\
\text { tecnológicamente }\end{array}$ & $92 \%$ & $100 \%$ \\
\hline & $\begin{array}{l}\text { Reconocimiento del potencial } \\
\text { pedagógico de TIC }\end{array}$ & $92 \%$ & $100 \%$ \\
\hline
\end{tabular}

Fuente: elaboración propia.

Tabla 11. Componente competencias TIC y desarrollo profesional. Resultados de la encuesta

\begin{tabular}{|c|c|c|c|}
\hline \multirow{2}{*}{ 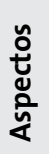 } & \multirow{2}{*}{ Criterios } & \multicolumn{2}{|c|}{$\begin{array}{l}\text { Valoración } \\
\text { alta }\end{array}$} \\
\hline & & IE1 & IE2 \\
\hline \multirow{3}{*}{ 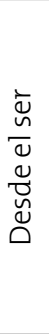 } & $\begin{array}{l}\text { Impacto positivo en el } \\
\text { desarrollo docente }\end{array}$ & $92 \%$ & $96 \%$ \\
\hline & $\begin{array}{l}\text { Motivación para abordar } \\
\text { procesos de formación } \\
\text { mediados por TIC }\end{array}$ & $92 \%$ & $96 \%$ \\
\hline & $\begin{array}{l}\text { Motivación para abordar } \\
\text { procesos de autoformación } \\
\text { mediados por TIC }\end{array}$ & $92 \%$ & $96 \%$ \\
\hline \multirow{2}{*}{ 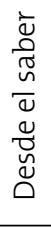 } & $\begin{array}{l}\text { Conocimiento de plataforma } \\
\text { e-learning y recursos Web }\end{array}$ & $92 \%$ & $64 \%$ \\
\hline & $\begin{array}{l}\text { Conocimiento de TIC para } \\
\text { participar en comunidades y } \\
\text { grupos virtuales }\end{array}$ & $83 \%$ & $64 \%$ \\
\hline \multirow{2}{*}{ 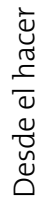 } & $\begin{array}{l}\text { Utilización de TIC para adquirir } \\
\text { conocimientos }\end{array}$ & $92 \%$ & $89 \%$ \\
\hline & $\begin{array}{l}\text { Participación en comunidades } \\
\text { y grupos de discusión }\end{array}$ & $67 \%$ & $54 \%$ \\
\hline
\end{tabular}

Fuente: elaboración propia.
Tabla 12. Componente competencias TIC, compromiso social y uso ético. Resultados de la encuesta

\begin{tabular}{|c|c|c|c|}
\hline \multirow{2}{*}{ 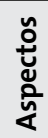 } & \multirow{2}{*}{ Criterios } & \multicolumn{2}{|c|}{$\begin{array}{l}\text { Valoración } \\
\text { alta }\end{array}$} \\
\hline & & IE1 & IE2 \\
\hline \multirow{2}{*}{$\begin{array}{l}\bar{\Delta} \\
\bar{u} \\
\ddot{u} \\
\bar{u} \\
\Delta\end{array}$} & $\begin{array}{l}\text { Reconocimiento de las TIC en la } \\
\text { democratización del conocimiento }\end{array}$ & $83 \%$ & $89 \%$ \\
\hline & $\begin{array}{l}\text { Motivación para participar en } \\
\text { proyectos de uso social de las TIC }\end{array}$ & $92 \%$ & $82 \%$ \\
\hline \multirow{2}{*}{ 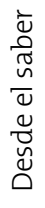 } & $\begin{array}{l}\text { Conocimiento de las TIC para } \\
\text { promover participación ciudadana }\end{array}$ & $67 \%$ & $89 \%$ \\
\hline & $\begin{array}{l}\text { Conocimiento de las TIC para } \\
\text { promover inclusión social }\end{array}$ & $67 \%$ & $89 \%$ \\
\hline \multirow{2}{*}{ 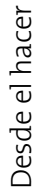 } & $\begin{array}{l}\text { Fomento de comunicaciones en los } \\
\text { procesos de convivencia ciudadana }\end{array}$ & $75 \%$ & $75 \%$ \\
\hline & $\begin{array}{l}\text { Conocimientos de los aspectos } \\
\text { legales en el uso de recursos digitales }\end{array}$ & $67 \%$ & $68 \%$ \\
\hline
\end{tabular}

Fuente: elaboración propia.

Según los resultados, los docentes están en capacidad de realizar procesos de gestión académica y tienen una actitud positiva y propositiva para la mejora de los mimos. En la encuesta, los criterios del componente de organización y gestión son valorados como alto por un $78 \%$ de los docentes (Tabla 13).

Tabla 13. Componente competencias TIC organización y gestión. Resultados de la encuesta

\begin{tabular}{|c|c|c|c|}
\hline \multirow{2}{*}{ 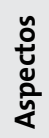 } & \multirow{2}{*}{ Criterios } & \multicolumn{2}{|c|}{$\begin{array}{l}\text { Valoración } \\
\text { alta }\end{array}$} \\
\hline & & IE1 & IE2 \\
\hline \multirow{2}{*}{ 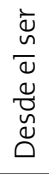 } & $\begin{array}{l}\text { Actitud colaborativa con los colegas } \\
\text { en el uso de las TIC }\end{array}$ & $75 \%$ & $79 \%$ \\
\hline & $\begin{array}{l}\text { Actitud propositiva para mejorar los } \\
\text { procesos de gestión }\end{array}$ & $75 \%$ & $89 \%$ \\
\hline \multirow{4}{*}{ 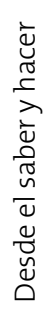 } & $\begin{array}{l}\text { Uso de TIC y de sistemas de } \\
\text { información en la gestión curricular }\end{array}$ & $83 \%$ & $79 \%$ \\
\hline & $\begin{array}{l}\text { Asistencia y seguimiento mediante } \\
\text { formatos digitales }\end{array}$ & $83 \%$ & $68 \%$ \\
\hline & $\begin{array}{l}\text { Comunicación entre la comunidad } \\
\text { académica con TIC }\end{array}$ & $92 \%$ & $68 \%$ \\
\hline & $\begin{array}{l}\text { Preparación de material didáctico } \\
\text { con TIC }\end{array}$ & $75 \%$ & $68 \%$ \\
\hline
\end{tabular}

Fuente: elaboración propia. 
En las encuestas se encuentra que la mayoría de los docentes tienen habilidades y destrezas técnicas en el manejo del hardware y software básico. Adicionalmente, parece superada la brecha afectiva para el uso de las TIC por un $92 \%$ de los profesores (Tabla 14).

Las entrevistas a docentes confirman los resultados anteriores, señalando además el uso de programas específicos de las áreas de matemáticas y sociales, tales como: Matlab, Geogebra, Tangram, Google Earth, Tetris, Cabri, juegos matemáticos, YouTube, Discovery channel y National geografic. Los investigadores de las IE valoraron los componentes de la dimensión humana con los siguientes promedios (Tabla 15).

Tabla 14. Componente competencias TIC - habilidades y destrezas técnicas. Resultados de la encuesta

\begin{tabular}{|c|c|c|c|}
\hline \multirow{2}{*}{ 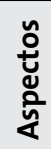 } & \multirow[b]{2}{*}{ Criterios } & \multicolumn{2}{|c|}{ Valoración alta } \\
\hline & & IE1 & IE2 \\
\hline 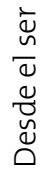 & $\begin{array}{l}\text { Regulación dimensiones } \\
\text { afectivas }\end{array}$ & $92 \%$ & $92 \%$ \\
\hline \multirow{7}{*}{ 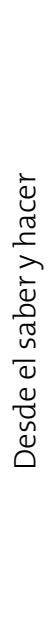 } & Computador y periféricos & $92 \%$ & $98 \%$ \\
\hline & Ofimática & $83 \%$ & $90 \%$ \\
\hline & $\begin{array}{l}\text { Correo electrónico, } \\
\text { navegadores, herramientas } \\
\text { web } 2.0\end{array}$ & $94 \%$ & $87 \%$ \\
\hline & Producción multimedial & $92 \%$ & $86 \%$ \\
\hline & Plataformas e-learning & $67 \%$ & $68 \%$ \\
\hline & $\begin{array}{l}\text { Solución de problemas } \\
\text { técnicos básicos }\end{array}$ & $50 \%$ & $54 \%$ \\
\hline & $\begin{array}{l}\text { Transferencia de } \\
\text { conocimientos para el } \\
\text { aprendizaje autónomo de } \\
\text { nuevos programas }\end{array}$ & $83 \%$ & $75 \%$ \\
\hline
\end{tabular}

Fuente: elaboración propia.
Tabla 15. Línea Base de Indicadores TIC - dimensión humana

\begin{tabular}{|l|c|c|}
\hline \multicolumn{1}{|c|}{ Componente } & IE1 & IE2 \\
\hline Competencia TIC - Pedagógica & $79 \%$ & $80 \%$ \\
\hline $\begin{array}{l}\text { Competencia TIC - Desarrollo } \\
\text { profesional }\end{array}$ & $75 \%$ & $88 \%$ \\
\hline $\begin{array}{l}\text { Competencia tic - Compromiso social } \\
\text { yético }\end{array}$ & $74 \%$ & $86 \%$ \\
\hline $\begin{array}{l}\text { Competencia tic - Organización y } \\
\text { gestión }\end{array}$ & $83 \%$ & $86 \%$ \\
\hline $\begin{array}{l}\text { Competencia TIC - Habilidades } \\
\text { técnicas }\end{array}$ & $79 \%$ & $75 \%$ \\
\hline Promedios & $78 \%$ & $83 \%$ \\
\hline
\end{tabular}

Fuente: elaboración propia.

\section{Dimensión material}

La dimensión material hace referencia a la infraestructura tecnológica de la institución educativa que soporta los procesos académicos y administrativos. En ambas IE, los docentes y directivos entrevistados expresan que debe mejorarse toda la infraestructura tecnológica para el uso académico y administrativo. Los resultados de las encuestas a docentes (Tabla 16) muestran que solo $18 \%$ califican como alta la infraestructura tecnológica. Llama la atención que la conectividad solo sea valorada como alta por $7 \%$ de los docentes y en consecuencia el acceso a portales y bibliotecas digitales lo sea por un $10 \%$; y es de notar que se sigue priorizando la disponibilidad de los pocos equipos para las clases de tecnología, a pesar de que se cuenta con políticas orientadas al uso equitativo de los recursos tecnológicos indistintamente del área de desempeño.

Los investigadores de las IE valoraron la infraestructura tecnológica, único componente de esta dimensión, con los promedios que se visualizan en la Tabla 17.

Por último, es de anotar que, a pesar de haber logrado el levantamiento de la línea base de indicadores y la construcción de planes de mejoramiento, el propósito de empoderar a la comunidad académica, necesario para la implementación de la Metodología 
ISSN 0123-1294 | e-ISSN 2027-5358 | Educ.Educ. Vol. 21. No.3 | Septiembre-diciembre de 2018 | pp. 435-457.

Universidad de La Sabana | Facultad de Educación

para la autoevaluación TIC, solo se alcanzó parcialmente, logrando el objetivo únicamente con algunos docentes. Este tipo de procesos de formación/ investigación requiere del compromiso de todas las partes implicadas (directivos, docentes, estudiantes y asesores externos). En este sentido, por parte de las
IE no se contó con los espacios y tiempos de trabajo necesarios, se cambió permanentemente la configuración y número de integrantes y fue irregular la asistencia a las actividades por parte de los investigadores internos, lo que dificulta la apropiación de la propuesta metodológica.

Tabla 16. Componente Infraestructura tecnológica

\begin{tabular}{|c|c|c|c|}
\hline \multirow{2}{*}{ Aspectos } & \multirow{2}{*}{ Criterios } & \multicolumn{2}{|c|}{ Valoración alta } \\
\hline & & IE1 & IE2 \\
\hline \multirow{4}{*}{$\begin{array}{l}\text { Aplicaciones y } \\
\text { herramientas }\end{array}$} & Disponibilidad de software de ofimática & $58 \%$ & $50 \%$ \\
\hline & Disponibilidad de software en computadores docentes para crear contenidos digitales & $25 \%$ & $14 \%$ \\
\hline & Disponibilidad de software en salas de computadores para crear contenidos digitales & $25 \%$ & $11 \%$ \\
\hline & Disponibilidad de plataformas e-learning & $25 \%$ & $11 \%$ \\
\hline \multirow{2}{*}{ Conectividad } & Ancho de banda & O\% & $7 \%$ \\
\hline & Disponibilidad de redes inalámbricas & $8 \%$ & $11 \%$ \\
\hline \multirow{7}{*}{ Equipos } & Relación profesores vs. computadores con internet & $17 \%$ & $11 \%$ \\
\hline & Grado de actualización tecnológica de equipos docentes & $17 \%$ & $29 \%$ \\
\hline & Relación número estudiantes vs. computadores con internet & $8 \%$ & $18 \%$ \\
\hline & Disponibilidad de salas de cómputo para clases de tecnología & $25 \%$ & $14 \%$ \\
\hline & Disponibilidad de salas de cómputo para otras clases & O\% & $7 \%$ \\
\hline & Grado de actualización tecnológica de equipos de salas & $17 \%$ & $14 \%$ \\
\hline & Disponibilidad de periféricos & $8 \%$ & $14 \%$ \\
\hline \multirow{2}{*}{$\begin{array}{l}\text { Recursos } \\
\text { educativos } \\
\text { digitales }\end{array}$} & Acceso a portales y bibliotecas digitales & $9 \%$ & $11 \%$ \\
\hline & Disponibilidad de sitio web institucional & $75 \%$ & $7 \%$ \\
\hline
\end{tabular}

Fuente: elaboración propia.

Tabla 17. Línea Base de Indicadores TIC - dimensión material

\begin{tabular}{|c|c|c|}
\hline Componente & IE1 & IE2 \\
\hline Infraestructura tecnológica & $52 \%$ & $54 \%$ \\
\hline
\end{tabular}

Fuente: elaboración propia. 


\section{Discusión}

Teniendo como precepto que para la apropiación tecnológica en la IE es necesario la integración de las TIC al currículo, los resultados muestran que se han dado transformaciones en lo macrocurricular; en este sentido, Erstad (2009) e Hincapié y Gómez (2014) reconocen que la existencia de directrices TIC curriculares en los documentos institucionales impactan positivamente las prácticas pedagógicas. Sin embargo, los resultados del presente estudio muestran que faltan mayores comprensiones, reflexión, participación y socialización en comunidad académica para que las TIC impacten lo microcurricular. Otros estudios, como los de Cano (2015), Díaz (2012) y Said, Valencia y Silveira (2016), llegan a conclusiones similares.

En esta experiencia investigativa se evidencia que, cuando el PEI se fundamenta en el trabajo por proyectos mediados tecnológicamente, ello deriva en procesos de enseñanza y de aprendizaje que obligan a una mayor apropiación de las TIC por parte de los docentes. Esto también lo concluyen Rogers, Cross, Gresalfi, Trauth y Buck (2010) luego de la implementación de un enfoque de aprendizaje basado en proyectos en el que encuentran que el currículo por sí solo no cambia la práctica. Los docentes con quienes desarrollaron el proyecto trabajaron con un currículo novedoso, y aunque hicieron cambios superficiales en su práctica, desde su percepción, consideraron la realización de cambios significativos en ella. Esto, como ya se ha expuesto y lo reiteran los autores, depende de la formación de los maestros, el apoyo continuo en el aula (con tecnología y desarrollo de currículo) y la colaboración y compromiso del personal de la escuela.

Los docentes son conscientes de las oportunidades educativas que brindan las TIC, tienen una actitud positiva hacia su uso y muestran niveles de apropiación, especialmente en la comunicación por medio del correo electrónico y la planeación de actividades haciendo uso de ofimática, navegadores y recursos digitales (videos y audios). Sin embargo, falta comprensión de las implicaciones pedagógicas que tiene la mediación tecnológica en los procesos educativos, lo que, como lo expresan Morales y Rojas (2016), responde al distanciamiento entre lo teórico y lo práctico en lo referente al uso de las TIC.

En el discurso de los docentes es recurrente que, al referirse a la mediación tecnológica en los procesos de interacción, indagación e investigación, escritura, lectura y evaluación, se haga alusión a uno de los elementos del proceso comunicativo: el canal (Google, correo electrónico, Whatsapp y Facebook), mas no a las intencionalidades de su uso. De allí que no sean claras las posibilidades que les brindan las TIC para favorecer, entre otras cosas: el pensamiento crítico (a través de los procesos de interacción e indagación), el desarrollo de la autonomía que viabiliza la evaluación (autoevaluación, heteroevaluación y coevaluación) y el desarrollo de competencias comunicativas por medio de la lectura hipertextual e hipermedial.

En este mismo sentido, se presentan resultados similares a los enunciados en el párrafo anterior, al aplicar esta Metodología en distintas instituciones educativas con propósitos investigativos por estudiantes de la Maestría en Educación de la UPB, énfasis en Ambientes de Aprendizaje Mediados por TIC (Oquendo y Rodríguez, 2012; Peláez, Tamayo y López, 2012; Hincapié y Gómez, 2014; Lombana, 2016; Morales y Rojas, 2016).

Los esfuerzos realizados por los entes gubernamentales en la formación de los docentes son evaluados de forma positiva por la comunidad académica, pues han permitido, en el discurso del docente, de un lado, disminuir la brecha afectiva, por la superación de temores respecto del uso de la tecnología, y de otro, el desarrollo de competencias TIC en relación con los campos pedagógico, social, ético, de formación profesional, administrativo y técnico. Se muestra como un asunto por mejorar el conocimiento de las normas legales y el tratamiento de información, que, en últimas, favorecen el manejo ético de los recursos digitales. Sin embargo, otros 
estudios, como el de Giraldo (2015), evidencian, en la voz de los docentes, que, aunque los trayectos de las experiencias formativas y de usos han evolucionado, esta brecha aún persiste:

Definitivamente la mayoría de los docentes se "casan" con un modelo o método pedagógico y a través de toda su práctica solo lo desarrollan, con ello entonces corre peligro la estabilidad de la clase cuando emergen otras formas o modos, uno de ellos la virtualidad. Pareciera un mecanismo de defensa o supervivencia frente a lo desconocido (docente AVA_M2_C8, citado en Giraldo, 2015, p. 240).

La competencia implica un ser, un saber y un hacer en contexto, y el análisis de los criterios que dan cuenta del hacer muestra que falta apropiación en el uso pedagógico de las TIC, lo que lleva a pensar que hay vacíos en la formación, al no tener en cuenta las particularidades de los contextos socioculturales de la IE, como lo expresan Hernández et al. (2013). Estudios como los de Oquendo y Rodríguez (2012) y Peláez et al. (2012) corroboran el distanciamiento entre el ser-saber y el hacer, es decir, que los docentes valoran positivamente los procesos de formación que han posibilitado el desarrollo de competencias TIC, pero los usos no trascienden lo instrumental.

La infraestructura tecnológica es un asunto por mejorar. Se presentan: deficiencias en la conectividad y el soporte tecnológico; obsolescencia de equipos; baja disponibilidad de dispositivos periféricos; y limitaciones en el acceso a plataformas e-learning, bases de datos, catálogos de bibliotecas, portales educativos, bancos de objetos de aprendizaje, laboratorios y simuladores. La infraestructura tecnológica es una condición sine qua non de la apropiación y, por lo tanto, su planeación y uso deben estar articulados a la propuesta curricular. Hincapié y Gómez identifican la importancia de que la integración y la incorporación de TIC estén estrechamente relacionadas:
[...] en el Colegio Marymount, se encuentra que existe una incorporación; esto se debe a las politicas internas y al Plan Estratégico de Sistemas que tiene dentro de sus objetivos, además de la adecuación de la planta física, la dotación, el mantenimiento y la cualificación a la comunidad, haciendo que la gestión en materia de TIC sea dinámica y ágil con seguimientos y actualizaciones permanentes.

En tanto que en la IERU dicha gestión se encuentra supeditada a las políticas públicas y a las gestiones correspondientes a los lineamientos que se brindan desde la Secretaría de Educación Municipal, lo cual dilata los procesos. [...] Es de anotar que en ambas instituciones se requiere del mejoramiento en la conectividad (2014, p. 146).

La dotación de recursos tecnológicos y la infraestructura en las instituciones educativas debe ser adecuada a sus realidades y necesidades particulares (Trucano, 2016). Para ello la Metodología utilizada en este estudio propone, a partir de una línea base de indicadores, una autoevaluación periódica, en contexto y realizada por sus actores (Harvey y Newton, 2004), que complemente la mirada cuantitativa, que tradicionalmente se ha centrado en la infraestructura y la formación en competencias TIC de los docentes (Lugo, 2016).

La Metodología busca ampliar el panorama que implica el proceso de apropiación de TIC en las IE (Johannessen, 2009, Erstad 2009). Por ejemplo, para Fernández, Fernández y Rodríguez lo que afecta en mayor medida la integración TIC en las instituciones educativas es, además de la formación en competencias digitales y la dotación tecnológica, la "coordinación tecno-pedagógica, el uso pedagógico diseñado desde el currículo escolar y liderazgo efectivo que genere un clima de aceptación de las tecnologías como elemento de innovación educativa" (2018, p. 412). Estos procesos requieren de la vinculación de la comunidad educativa, de una visión a largo plazo y de políticas institucionales de apoyo 
que determinen condiciones estructurales que les brinden confianza, dominio y tiempo para su participación en los procesos de integración TIC (Becuwe et al., 2017), Además, demanda una mirada multidimensional y la evaluación permanente, que comprenda la complejidad de los procesos de enseñanza y de aprendizaje propios de cada institución, en el marco de las directrices y tendencias educativas emergentes que avizoran nuevos retos y desafíos.

\section{Conclusiones}

El ejercicio de autoevaluación de apropiación de las tecnologías de información y comunicación (TIC), en un contexto educativo como el de las Instituciones de Educación Básica y Media, exige de saberes previos, respecto tanto de los procesos de investigación educativa como de la apropiación de las TIC. Esto en razón de que los sujetos de la comunidad académica, que participan de un proyecto de investigación evaluativa, deben tener las herramientas conceptuales suficientes para el reconocimiento de las situaciones de enseñanza y de aprendizaje mediadas tecnológicamente, reconociendo el sentido y significado de la incorporación, integración y apropiación de TIC (EAV, 2006).

La Metodología para levantar la línea base de indicadores en apropiación de TIC propone la participación de diferentes actores educativos (estudiantes, maestros y administrativos), con el fin de garantizar que las valoraciones de la línea base de indicadores representen su realidad institucional desde el ser, el saber y el hacer, además de que la comunidad se empodere de los planes y proyectos orientados al mejoramiento de la apropiación TIC (Ángel et al., 2015).

La falta, por un lado, de formación conceptual y pedagógica en TIC y, por el otro, de participación activa, permanente y comprometida de los miembros de la comunidad académica deriva en una autoevaluación basada en las percepciones de unos pocos, lo que conlleva sobrevaloraciones o subvaloraciones -para el caso, de los indicadores de la línea base de apropiación TIC-y, consecuentemente, que las contribuciones de los planes de mejoramiento no transciendan a las instancias de toma de decisiones.

Igualmente, si los integrantes de las comunidades académicas que lideran estos proyectos no se forman y participan en investigación educativa, difícilmente podrán ser los artífices de las trasformaciones de sus prácticas en pro de la calidad, pues seguirán asumiendo los cambios propuestos por entes externos, tal como lo afirman Murillo y Perines: "si queremos que la investigación educativa comience a tener un impacto en la toma de decisiones de docentes y directivos escolares, es necesario que se produzca una transformación en las políticas de investigación educativa [...], en el trabajo de los investigadores y en el quehacer de docentes y directivos" (2017, p. 96).

La mirada holística a las TIC, encuadrada por las dimensiones teórica, práctica, humana y material, permite integrar lo instrumental y lo cuantitativo con un análisis más cualitativo de las fortalezas y aspectos a mejorar por parte de las IE en materia de apropiación tecnológica. Como aspectos positivos se resaltan: 1) el reconocimiento que hacen los docentes de la formación liderada por las secretarías de educación que impacta el desarrollo de las competencias de los docentes; 2) el uso generalizado de las TIC en las actividades de planeación de clases, comunicación de información y búsqueda de datos en la red; en algunas prácticas puntuales se evidencian procesos de coevaluación, interacción, indagación y divulgación por medio de redes sociales, blogs y páginas institucionales, y 3) la integración de las TIC en los $\mathrm{PEl}$, que comienza a permear los procesos académicos y administrativos.

Es importante señalar el impacto de las declaraciones del uso de las TIC en el PEI, como lo evidencia la comunidad académica de una IE, en la cual se declara un enfoque basado en la mediación tecnológica. En este sentido, se hacen esfuerzos en la integración de las áreas a través del 
trabajo por proyectos, y en la formación investigativa, el trabajo colaborativo, el seguimiento y la divulgación de los resultados de los proyectos de investigación de los estudiantes, con la comunidad tanto científica como académica.

Como aspectos por mejorar se encuentran: 1) la infraestructura tecnológica, cuyas deficiencias en términos de acceso y especialmente de conectividad desmotiva el desarrollo de actividades con TIC; 2) la insuficiente planeación estratégica en materia de TIC, en parte explicada por la centralización en las secretarías de educación de los procesos de formación docente, adquisición de infraestructura tecnológica y soporte técnico, lo que no exime a las IE de su responsabilidad en estos asuntos; 3) la ausencia de discusión académica sobre las políticas y propuestas TIC en comunidad, lo que dificulta las trasformaciones en lo microcurricular, y 4) la incorporación instrumental de las TIC en las IE, que exige pensar en una formación con mayor énfasis en lo conceptual y en la construcción de ambientes de aprendizaje mediados por TIC, de modo que se integre la diversidad de usos en los procesos y prácticas educativas.

La Metodología para la apropiación integral de TIC en la Institución Educativa permitió, en últimas, identificar, en sus dimensiones teórica, práctica, humana y material, las fortalezas y debilidades en los procesos de incorporación, integración y apropiación TIC en las IE. Los propósitos de empoderar a la comunidad académica en la autoevaluación permanente y en la construcción de unos indicadores valoradas cuantitativa y cualitativamente como producto de la discusión académica se lograron parcialmente. Para participar en este tipo de experiencia, las secretarías de educación y las IE deben garantizar la gestión de las condiciones, recursos e incentivos necesarios (Ortiz, 2013) para asumir un proceso de investigación educativa de manera metódica, rigurosa, sistemática y contextual.

Las limitaciones de esta experiencia investigativa son similares a las de otros estudios cualitativos. La primera es el tamaño de la muestra, con la que no es posible generalizar los resultados, asunto que no es de interés del estudio, que, por su naturaleza, busca lecturas del contexto particular de las instituciones. La segunda es que este es un primer ejercicio investigativo en cada IE, que arroja resultados similares a los de otros estudios, aunque el objetivo de la Metodología es que cada IE realice estas autoevaluaciones de manera permanente e identifique su progreso en términos de incorporación, integración y apropiación de TIC, tras implementar sus planes de mejoramiento, esto como insumo para que la institución se compare a sí misma periódicamente, lo cual tampoco hacía parte del alcance de este proyecto.

Este tipo de experiencias investigativas muestran que la apropiación TIC es un camino en el cual los responsables del sistema educativo, las instituciones y los sujetos que los conforman van marcando trayectos propios, siempre con el ideal de trabajar por la calidad educativa. Para usar las palabras de José Saramago, "parecía que habíamos llegado al final del camino y resulta que era sólo una curva abierta a otro paisaje y a nuevas curiosidades" (1998, p. 176). 


\section{Referencias}

Álvarez-Cadavid, G., Vega-Velásquez, A. y Álvarez, G. (2011). Apropiación de las TIC en comunidades vulnerables: el caso de Medellín digital. Apertura. Revista de Innovación Educativa, 14, 156-169. Recuperado de http:// www.udgvirtual.udg.mx/apertura/index.php/apertura/article/view/194

Ángel-Uribe, I. C., Patiño-Lemos, M. R., Peláez-Cárdenas, A. F. y Zambrano-Acosta, J. (2014). Las TIC potenciando la evaluación de las instituciones educativas. Ponencia presentada en el XV Encuentro Internacional Virtual Educa Perú, junio, Lima, Perú.

Ángel-Uribe, I. C., Patiño-Lemos, M. P., Peláez-Cárdenas, A. F.y Zambrano-Acosta, J (2015). Formación investigativa para la autoevaluación TIC en Instituciones Educativas. Ponencia presentada en el XVI Encuentro Virtual Educa, Guadalajara, México.

Ángel-Uribe, I. C., Patiño-Lemos, M. R. y Vallejo-Gómez, M. (2017). BaseTIC. Una metodología para la autoevaluación de apropiación TIC institucional. Medellín: Universidad Pontificia Bolivariana.

Ávila-Fajardo, G. P.y Riascos-Erazo, S. C. (2011). Propuesta para la medición del impacto de las TIC en la enseñanza universitaria. Educación y Educadores, 14(1), 169-188. DOI:10.5294/edu.2011.14.1.9

Becuwe, H., Pareja-Roblin, N., Tondeur, J., Thys, J., Castelein, E. y Voogt, J. (2017). Conditions for the successful implementation of teacher educator design teams for ICT integration: A Delphi study. Australasian Journal of Educational Technology, 33(2), 159-172. DOI: 10.14742/ajet.2789

Cano, J. A. (2015). Metodología para una evaluación del impacto en el uso y la apropiación de las TIC en el marco del plan digital teso: dimensiones humana y teórica de la Institución Educativa Loma Linda del municipio de Itagüí (Trabajo de grado de Maestría). Universidad Pontificia Bolivariana, Medellín, Colombia.

Castro, E. (2006). Una reflexión sobre la educación y la investigación pedagógica. La investigación debe ser una práctica transversal en la escuela. Entramado, 2(1), 94-104. Recuperado de http://www.unilibrecali.edu. co/images2/revista-entramado/pdf/pdf_articulos/volumen2/Una_reflexion_sobre_la_educacion_y_la_ investigacion_pedagogica.pdf

Cepal - Comisión Económica para América Latina y el Caribe (2015). Compendio de prácticas estadísticas sobre las tecnologías de la información y las comunicaciones en América Latina y el Caribe. Versión 2014. Serie Desarrollo Productivo No. 199, 1-132.

Chaves, A. L. (2001). Implicaciones educativas de la teoría sociocultural de Vigotsky. Revista Educación, 25(2), 5965. Recuperado de https://www.redaly c.org/articulo.oa?id=44025206

Claro, M. (2010), La incorporación de tecnologías digitales en educación. Modelos de identificación de buenas prácticas. Santiago de Chile: ONU.

Díaz-Barriga, F. (2012). Reformas curriculares y cambio sistémico: una articulación ausente pero necesaria para la innovación. Revista Iberoamericana de Educación Superior, 3(7), 23-40. Recuperado de http://www.scielo. org.mx/scielo.php?script=sci_arttext\&pid=S2007-28722012000200002 
EAV - Educación en Ambientes Virtuales (2006). Un modelo para la educación en ambientes virtuales. Medellín: Universidad Pontificia Bolivariana.

Erstad, O. (2009). Addressing the complexity of impact - A multilevel approach towards ICT in education. En F. Scheuermann y F. Pedró (eds.), Assessing the effects of ICT in education. Indicators, criteria and benchmarks for international comparisons (pp. 21-38). Luxemburgo: European Union/OECD.

Fernández-Cruz, F. J., Fernández-Díaz, M. J. y Rodríguez-Mantilla, J. M. (2018). El proceso de integración y uso pedagógico de las TIC en los centros educativos madrileños. Educación XX1, 21(2), 395-416. DOI: 10.5944/ educXX1.17907

Fuentes, J. S. (2013). Instrumento de autoevaluación institucional para identificar el nivel de madurez en innovación educativa con uso de TIC (Trabajo de grado de Maestría). Universidad Eafit, Medellín, Colombia.

García, J. L. (2003). Métodos de investigación en educación. Vol. II. Investigación cualitativa y evaluativa. Madrid: Universidad Nacional de Educación a Distancia.

Giraldo-Ramírez, M. E. (2006). Tecnología-comunicación-educación: La triada. Marco de referencia conceptual para la educación en ambientes virtuales. En EAV, Un modelo para la educación en ambientes virtuales (pp. 29-70). Medellín: Universidad Pontificia Bolivariana.

Giraldo-Ramírez, M. E. (2015). La mitificación de las tecnologías de la comunicación en la educación: actitudes, discursos y prácticas de los docentes universitarios colombianos (Tesis de Doctorado). Universitat Autònoma de Barcelona, Barcelona, España.

Giraldo-Ramírez, M. E. y Patiño-Lemos, M. R. (2009). Acercamiento a las estrategias de apropiación de Medellín digital en cuatro comunas de la ciudad: panorama conceptual y evidencias empíricas. Revista Q, 3(6), 1-24. Recuperado de https://revistas.upb.edu.co/index.php/revista_Q/article/view/7817

Harvey, L y Newton, J. (2004). Transforming quality evaluation. Quality in Higher Education, 10(2), 149-165. DOI: $10.1080 / 1353832042000230635$

Hernández, U.; Andrade, H. H.; Moreno, J. J; García, J. R; López, G. y Benavides, P. O. (2013). Evaluación y aprendizajes de una experiencia colombiana de formación docente en TIC. Revista Virtual, 40, 31-52. Recuperado de http://revistavirtual.ucn.edu.co/index.php/RevistaUCN/article/viewFile/444/934

Hincapié, M. T. y Gómez, R. H. (2014). Caracterización del uso y apropiación de las TIC en las prácticas de los docentes de ciencias naturales y exactas del Colegio Marymount y de la Institución Educativa República de Uruguay del Municipio de Medellín (Trabajo de grado de Maestría). Universidad Pontificia Bolivariana, Medellín, Colombia.

Hinostroza, J. E. y Labbé, C. (2011). Políticas y prácticas de informática educativa en América Latina y El Caribe. Serie Políticas Sociales, (171), 1- 83. Recuperado de https://www.cepal.org/es/publicaciones/6182-politicaspracticas-informatica-educativa-america-latina-caribe 
IE Loyola (2010). Proyecto educativo institucional de la Institución Educativa Colegio Loyola para la Ciencia y la Innovación. Medellín: Fundación Loyola, Alcandía de Medellín, SENA. Recuperado de https://media.master200o.net/uploads/252/PEI_13_DE_ABRIL.pdf

IE MUA (2014). Proyecto educativo institucional de la Institución Educativa Manuel Uribe Ángel. Envigado: MUA. Recuperado de http://studylib.es/doc/665193/-pei--de-la-instituci\%C3\%B3n-educativa-manuel-uribe

Johannessen, Ф. (2009). In search of the sustainable knowledge base: multi-channel and multi-method? En F. Scheuermann y F. Pedró (eds.), Assessing the effects of ICT in education. Indicators, criteria and benchmarks for international comparisons (pp.13-20). Luxemburgo: European Union/OECD.

Lombana, A. M. (2016). Competencias, uso y apropiación de TIC en los docentes del Colegio de la UPB: establecimiento de una línea base (Trabajo de grado de Maestría). Universidad Pontificia Bolivariana, Medellín, Colombia.

Lugo, C. (2016). Los retos de la política pública de innovación y TIC en educación. En MEN, La innovación educativa en Colombia. Buenas prácticas para la innovación y las TIC en educación (pp. 5-19). Bogotá: MEN.

Lugo, M. T. y Kelly, V. (2011). La matriz TIC. Una herramienta para planificar las Tecnologías de la Información y Comunicación en las instituciones educativas. Buenos Aires: Unesco.

MacBeath, J (2005). Schools must speak for themselves: The case for school self-evaluation. The case for school selfevaluation. Londres: Taylor \& Francis.

MEN (2006). Plan decenal de Educación 2006-2016. Bogotá: MEN.

Melgarejo, V. E.y Rodríguez, A. A. (2016). Integral schema for Monitoring and Evaluation of ICT Inclusion, Use and Appropriation in Education. Ponencia presentada en Unesco-Unir ICT \& Education Latam Congress 2016, Universidad Distrital Francisco José de Caldas, Bogotá, Colombia.

Ministerio de Comunicaciones (2008). Plan Nacional de Tecnologías de la Información y las Comunicaciones. Plan Nacional de TIC 2008-2019. Bogotá: Ministerio de Comunicaciones. Recuperado de http://eduteka. icesi.edu.co/pdfdir/ColombiaPlanNacionalTIC.pdf.

Mominó, J. M. y Carrere, J. (2016). A model for obtaining ICT indicators in education. Unesco Working Papers on Education Policy No. 3. Recuperado de http://unesdoc.unesco.org/images/0024/002442/244268e.pdf

Morales, H. Y. y Rojas, C. (2016). Estrategia de gestión curricular de las TIC en las instituciones educativas Bernardo Arango Macías y León XIII, sustentada en una línea base de indicadores desde una perspectiva multidimensional. (Trabajo de grado de Maestría). Universidad Pontificia Bolivariana, Medellín, Colombia.

Murillo, F. J. y Perines, H. A. (2017). Cómo los docentes no universitarios perciben la investigación educativa. Revista Complutense de Educación, 28(1), 81-99. DOI:10.5209/rev_RCED.2017.v28.n1.48800

OEl y Fundación Telefónica (2011). Integración de TIC en la escuela. Indicadores cualitativos y metodología de investigación. Madrid: OEl. Recuperado de http://www.oei.es/historico/noticias/spip.php?articleg607. 
Oquendo, N.y Rodríguez, L. M. (2012). Caracterización de las prácticas pedagógicas con integración de las TIC en el colegio de calidad presbitero Antonio José Bernal Londoño S.J. Municipio de Medellín (Trabajo de maestría). Universidad Pontificia Bolivariana, Medellín, Colombia.

Ortiz, I. (2013). Gestión curricular en las escuelas con tecnologías de la información y la comunicación. Sistematización de algunas experiencias en Chile. Perfiles Educativos, 35(141), 152-166. DOI: 10.1016/So1852698(13)71840-3

Patiño, J. A. (2013). Lista de indicadores para el eLAC2015: versión 2013. Santiago de Chile: Cepal. Recuperado de http://www.cepal.org/es/publicaciones/4052-lista-indicadores-elac2015-version-2013.

Patiño-Lemos, M. R. y Vallejo-Gómez, M. (2013). Indicadores de apropiación TIC en instituciones educativas. Revista Educación y Desarrollo Social, 7(1), 41-52. DOI: 10.18359/reds.732

Peláez, I. C.; Tamayo, L. H.y López, H. A. (2012). La práctica de enseñanza de los docentes que culminaron el momento de apropiación profesional de la ruta de formación docente en TIC del municipio de Medellín (Trabajo de grado de Maestría). Universidad Pontificia Bolivariana, Medellín, Colombia.

Peeraer, J. y Van Petegem, P. (2011). Measuring integration of information and communication technology in education: An item response modeling approach. Computers \& Education, 58(4), 1247-1259. DOI: 10.1016/j. compedu.2011.12.015

Rodríguez, L. M. y Ocampo, N. A. (2014). La apropiación de las TIC en el discurso sobre las prácticas docentes en el colegio de la UPB: análisis desde una perspectiva wittgensteiniana del lenguaje (Trabajo de grado de Maestría). Universidad Pontificia Bolivariana, Medellín, Colombia.

Rogers, A. P., Cross, D. I., Gresalfi, M. S., Trauth-Nare, A. E.y Buck, G. A. (2010). First year implementation of a projectbased learning approach: the need for addressing teachers' orientations in the era of reform. International Journal of Science and Mathematics Education, 9(4), 893-917. DOI: 10.1007/s10763-010-9248-x

Said, E.; Valencia, J. y Silveira, A. (2016). Factores determinantes del aprovechamiento de las TIC en docentes de educación básica en Brasil. Un estudio de caso. Perfiles Educativos, 38(151), 71-85. Recuperado de http:// www.scielo.org.mx/scielo.php?script=sci_arttext\&pid=S0185-26982016000100071

Saramago, J. (1998). El año de la muerte de Ricardo Reis. Madrid: Alfaguara.

Severin, E. (2010). Tecnologías de la información y la comunicación (TICS) en educación. Marco conceptual e indicadores. Chile: Banco Interamericano de Desarrollo. Recuperado de https://goo.gl/pgjB5o.

Sunkel, G. (2006). Las tecnologías de la información y la comunicación (TIC) en la educación en América Latina. Una exploración de indicadores. Serie Politicas Sociales, (126), 1-70.

Tamayo, D. M. y Restrepo, E. A. (2015). Caracterización de las prácticas de enseñanza de docentes que manifiestan hacer uso de TIC: En dos instituciones educativas oficiales que participan en el programa CIER Occidente (Trabajo de grado de maestría). Universidad Pontificia Bolivariana, Medellín, Colombia. 
Taquez, H., Rengifo, D. y Mejía, D. (2017). Diseño de un instrumento para evaluar el nivel de uso y apropiación de las TIC en una institución de educación superior. Recuperado de http://recursos.portaleducoas.org/sites/ default/files/5030.pdf

Trucano, M. (2016). Saber-ICT framework paper for policy analysis: Documenting national educational technology policies around the world and their evolution over time. World Bank Education, Technology \& Innovation: SABER-ICT Technical Paper Series (\#01). Washington: The World Bank.

UIT (2010). Partnership para la Medición de las TIC para el desarrollo. Indicadores clave sobre TIC, 2010. Ginebra: Unión Internacional de Telecomunicaciones. Recuperado de http://www.itu.int/dms_pub/itu-d/opb/ ind/D-IND-ICT_CORE-2010-PDF-S.pdf

Unesco (2009). Medición de las Tecnologías de la Información y Comunicación (TIC) en Educación -Manual de usuario. Montreal: Unesco. Recuperado de http://unesdoc.unesco.org/images/o018/001883/188309s.pdf

Valencia-Molina, T., Serna-Collazos, A., Ochoa-Angrino, S. Caicedo-Tamayo, A. M., Montes-González, J. A. y ChávezVescance,J. D. (2016). Competencias y estándares TIC desde la dimensión pedagógica: Una perspectiva desde los niveles de apropiación de las TIC en la práctica educativa docente. Cali: Pontificia Universidad Javeriana.

Vallejo-Gómez, M. y Patiño-Lemos, M. R. (2011). Caracterización de prácticas con TIC por actores diferenciados en cuatro comunas de la ciudad de Medellín: un abordaje para el reconocimiento de la apropiación tecnológica. Revista Q, 5(10), 1-31. Recuperado de https://revistas.upb.edu.co/index.php/revista_Q/article/view/7791

Vallejo-Gómez, M. y Patiño-Lemos, M. R. (junio, 2013). Metodología para la apropiación integral de TIC en la Institución Educativa. Ponencia presentada en XIV Encuentro Internacional Virtual Educa, Medellín, Colombia.

Vallejo-Gómez, M. y Patiño-Lemos, M. R. (2014). Instrumentos para evaluar apropiación tecnológica en instituciones educativas. Revista Q, 9(17), 1-25. Recuperado de https://revistas.upb.edu.co/index.php/revista_O/ article/view/7724 
